\title{
Blood and Bone Marrow Changes in Elderly Patients, with Special Reference to Folic Acid, Vitamin $B_{12}$, Iron, and Ascorbic Acid
}

\author{
M. BATATA,* M.D.; G. H. SPRAY, † B.SC., M.A., D.PHIL.; F. G. BOLTON, $¥$ M.D., M.R.C.P., M.C.PATH. \\ G. HIGGINS,§ B.SC. ; L. WOLLNER,g M.B., M.R.C.P.
}

Brit. med. F., 1967, 2, 667-669

The prevalence of anaemia and the occasional unexpected finding of low serum folic acid and vitamin- $\mathrm{B}_{12}$ concentrations in aged inpatients prompted this investigation.

Anaemia, usually with normoblastic haemopoiesis, is common in the elderly (Bedford and Wollner, 1958; Lawson, 1960 ; Geill, 1962). Serum folic acid concentrations may be in the lower half of the range found in younger healthy people (Hansen and Nyström, 1961), while decreased serum folic acid levels in 40 out of 50 entrants to an old people's home, with increased excretion of formiminoglutamic acid in 31 of the 50, have been reported by Read et al. (1965). Reduced intake of food was thought to be the likely cause of folic acid deficiency in this group. Fifteen of a group of 50 apparently healthy aged subjects living at home also had serum folic acid concentrations below the range accepted as normal by Read et al. The serum vitamin- $B_{12}$ concentration has been found to be reduced in old people (Mollin and Ross, 1952 ; Boger et al., 1955 ; Chow et al., 1956 ; Gaffney et al., 1957 ; Cape and Shinton, 1961 ; Geill, 1962) though some authors could not confirm this (Killander, 1957). Droller and Dossett (1959) found that, although age itself had no effect on the serum vitamin- $B_{12}$ concentration, patients with confusion or with senile dementia had significantly lower concentrations. The amount of ascorbic acid in the leucocytes of old people who had been living at home has been found to be abnormally low (Denson and Bowers, 1961).

A survey by the King Edward's Hospital Fund for London (1965) has shown progressive reduction in food intake with increasing age in healthy women living alone.

\section{Patients Studied and Methods Used}

One hundred consecutive patients newly admitted to the care of one of us (L.W.) at Cowley Road Hospital, Oxford, were studied. Patients who had received antibiotics, chemotherapy, or blood transfusion within two weeks before admission or folic acid, vitamin $B_{12}$, ascorbic acid, or vitamin supplements within one month before admission were excluded. Of the patients studied, 27 men and 73 women, the normal sex distribution for the hospital, 12 were aged 60-69, 49 were aged 70-79, and 39 were aged 80 and over (Table I).

All patients had a full clinical assessment, which was recorded in detail on a prescribed form. Dietary and social history was also recorded.

TABLE I.-Distribution of Patienis Aged 60 and Over According to Age

\begin{tabular}{c|c|c|c}
\multicolumn{4}{|c}{ and Sex } \\
\hline \multirow{2}{*}{ Age } & \multicolumn{3}{|c}{ No. of Patients } \\
\cline { 2 - 4 } & Male & Female & Total \\
\hline $60-64$ & 1 & 5 & 6 \\
$65-69$ & 1 & 5 & 6 \\
$70-74$ & 6 & 13 & 19 \\
$75-79$ & 9 & 21 & 24 \\
$80-84$ & 6 & 8 & 11 \\
$85-89$ & 3 & 3 & 4 \\
90 and over & 1 & 73 & 100 \\
\hline & 27 & &
\end{tabular}

Haemoglobin concentration and blood counts were done on venous blood by standard methods.

Bone-marrow Examination.-Ninety-four patients submitted to bone-marrow examination. Bone-marrow films were stained by the May-Grünwald-Giemsa sequence and also for haemosiderin with a filtered mixture of $2 \%$ potassium ferrocyanide solution and $2 \%$ hydrochloric acid maintained at $56^{\circ} \mathrm{C}$. for 20 minutes. The percentage of normoblasts containing haemosiderin (sideroblasts) was determined and the marrow was classified into four grades depending on this percentage (grade 1, $0-10 \%$; grade 2 , $11-20 \%$; grade $3,21-50 \%$; grade $4,51 \%$ and over). Values over $20 \%$ were considered to be normal, in keeping with the normal ranges of 16-69\% (Lawrence, 1959), 24-81\% (Douglas and Dacie, 1953), and 20-90\% (Kaplan et al., 1954).

Serum vitamin- $B_{12}$ estimations were made by the method of Spray (1955), Lactobacillus leichmannii being used. The normal range by this method on 222 subjects studied during 1964-6 was 140-1,200 $\mu \mu \mathrm{g}$./ml. of serum (Spray, unpublished observations). Only 168 of these subjects are included in this survey.

Serum folic acid estimations were made by the method of Spray (1964), L. casei being used. The normal range is 2.1$28 \mathrm{~m} \mu \mathrm{g} . / \mathrm{ml}$. of serum.

Blood ascorbic acid was measured by the method of Roe and Kuether (1943), using 2,4-dinitrophenylhydrazine.

\section{Results}

The patients showed clinical evidence of a wide range of disorders-57 had ischaemic cerebral disease, 31 had ischaemic heart disease, eight had malignant disease, eight had fractures of femur or humerus, two had frank bleeding from the gastrointestinal tract, two others had peptic ulceration, two had malabsorption, and four had rheumatoid arthritis.

\section{Anaemia and Bone-marrow Results}

Anaemia, defined as a haemoglobin concentration of 11.7 g./100 ml. or less, was present in 33 patients. Ten of these had a hypochromic anaemia with a mean corpuscular haemoglobin concentration (M.C.H.C.) of $30 \%$ or less and a diminished sideroblast count (grades 1 and 2 ) in the bonemarrow film. Six were anaemic with M.C.H.C. $30-31.9 \%$ and a diminished sideroblast count, and two had a normochromic anaemia with a diminished sideroblast count. Thirteen with a normochromic anaemia and two with a hypochromic anaemia had large numbers of sideroblasts in the bone marrow (grades 3 and 4 ).

\footnotetext{
* Research Assistant, Nuffield Department of Clinical Medicine, United Oxford Hospitals.

† Research Officer, Nuffield Department of Clinical Medicine, United Oxford Hospitals.

‡ Consultant Clinical Pathologist, United Oxford Hospitals.

$\$$ Biochemist, Nuffield Department of Clinical Biochemistry, United Oxford Hospitals. 9 Consultant Physician, Departments of Medicine and of Geriatric Medl-
cine, United Oxford Hospitals.
} 
Sixty-seven patients were not anaemic on admission. In 5 the bone marrow was not examined, in 39 the marrow film showed decreased numbers of sideroblasts (grades 1 and 2), and in 24 sideroblasts were numerous.

Haemopoiesis was normoblastic in all cases except one, a woman with reticulosarcoma. Examination of the bone marrow showed a macronormoblastic form of haemopoiesis and the serum vitamin $\mathrm{B}_{12}$ was $310 \mu \mu \mathrm{g} . / \mathrm{ml}$. and serum folic acid 3.2 $\mathrm{m} \mu \mathrm{g} . / \mathrm{ml}$.

The bone marrow appeared to be of poor cellularity in 21 patients, but in only three of these was the haemoglobin concentration below $11.7 \mathrm{~g} . / 100 \mathrm{ml}$.

\section{Serum Folic Acid Concentration (See Fig. 1)}

The range obtained in 93 control subjects drawn from hospital staff and visitors was $2.1-28 \mathrm{~m} \mu \mathrm{g} . / \mathrm{ml}$. The mean of 79 control subjects aged $17-59$ was $7.8 \mathrm{~m} \mu \mathrm{g}$., nine of whom had values between 2.1 and 3 , and the mean of 14 control subjects aged 60 and over was 7.7.

The sera of 99 patients tested gave a range of $0.8-17$ $\mathrm{m} \mu \mathrm{g} . / \mathrm{ml}$., with a mean of 4.7 . Twenty patients had values between 2.1 and $3 \mathrm{~m} \mu \mathrm{g} . / \mathrm{ml}$. The difference between the means of the patients and of the younger control group was highly significant $(\mathrm{P}<0.001)$. The number of older subjects was insufficient for statistical analysis. There was no obvious difference in levels between the two control groups.

The patients with rheumatoid arthritis, malignant disease, and malabsorption all had levels in the normal range.

\section{Serum Vitamin-B ${ }_{12}$ Concentration (See Fig. 2)}

The range obtained in 168 control subjects drawn from hospital staff and visitors was 140-1,200 $\mu \mu \mathrm{g} . / \mathrm{ml}$. The mean of 106 control subjects aged 10-59 years was 425 and of 62 control subjects aged 60 years and over was 429 . Forty-one of the combined group had values below 300, with none below 140.

The sera of 98 patients gave a range of $110-880 \mu \mu \mathrm{g} . / \mathrm{ml}$, with a mean of 359.6. Fifty had concentrations below 300 and three were below 140. At concentrations of 120,120, and
110 , these levels were not as low as is usually found in untreated pernicious anaemia. The difference between the mean of the patients and the mean of each of the two control groups was highly significant $(P<0.01)$.

There was no tendency in the control groups for the vitamin- $B_{12}$ concentration to fall with age.

\section{Organic Brain Disease}

The mean serum folic acid concentration in our patients with evidence of organic brain disease was $3.9 \mathrm{~m} \mu \mathrm{g} . / \mathrm{ml}$., whereas that in patients without evidence of organic brain disease was $5.8 \mathrm{~m} \mu \mathrm{g} . / \mathrm{ml}$., a difference which is statistically significant $(\mathrm{P}<0.001)$. All patients with levels below $2.1 \mathrm{~m} \mu \mathrm{g} . / \mathrm{ml}$. had evidence of organic brain disease (Fig. 3). The mean serum vitamin- $B_{12}$ concentration in the same group of patients with evidence of organic brain disease was $348 \mu \mu \mathrm{g} . / \mathrm{ml}$. and that of the group without such evidence was $376 \mu \mu \mathrm{g}$. $/ \mathrm{ml}$., a difference which is not significant $(P>0.10)$. Criteria of organic brain disease were the presence of abnormal neurological signs localized to the brain, all of the patients with these signs having recent or old cerebrovascular disease or, in two patients, persistent mental impairment with air-encephalograms suggesting cortical atrophy.

\section{Blood Ascorbic Acid Concentration}

Twenty patients had values below $0.2 \mathrm{mg} . / 100 \mathrm{ml}$. Nine had values of $0.1 \mathrm{mg} . / 100 \mathrm{ml}$. or less; all nine were admitted to hospital in the winter months.

TABlb II.-Serum Folic Acid Concentrations in Patients Aged 60 and Over, According to Social State

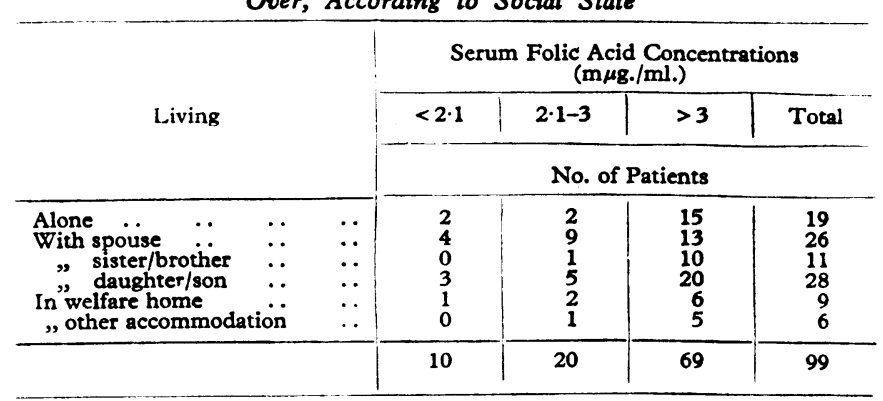

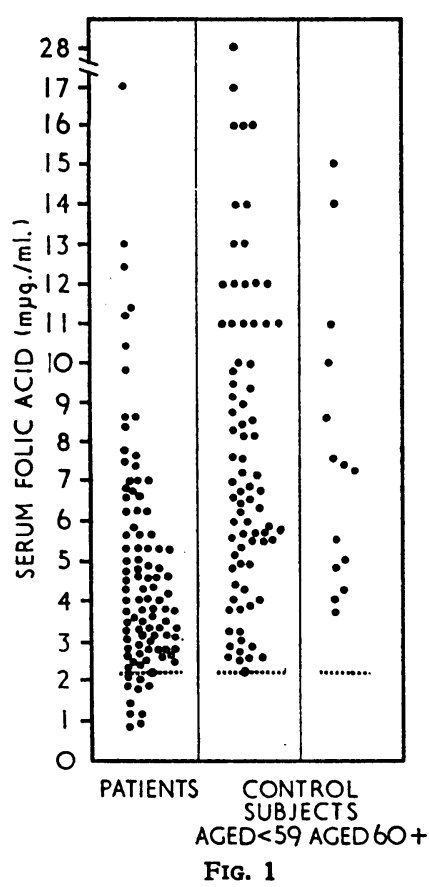
FIG. 1. - Serum folic acid concentrations in patients aged 60 and over and in control subjects. FIG. 2.-
Serum vitamin-B. folic acid concentrations in patients aged 60 and over, with and without organic brain disease. 
Values below $0.2 \mathrm{mg} . / 100 \mathrm{ml}$. were commonly found in normal subjects taking $10 \mathrm{mg}$. or less of ascorbic acid a day (Medical Research Council, 1953), though values as low as $0.06 \mathrm{mg}$. were occasionally found with $20 \mathrm{mg}$. a day intake.

No statistically significant relation could be found between the following values: haemoglobin concentration, sideroblast count, and serum folic acid, serum vitamin- $B_{12}$, and blood ascorbic acid concentrations when taken in pairs. There was no correlation between serum folic acid concentration and social state (Table II).

\section{Discussion}

The spectrum of clinical disease encountered in this group of patients has been briefly described. It was not a group in which such haematological and vitamin assay findings would normally be expected.

A third of the patients were anaemic and a tenth had a frank iron-deficiency anaemia. In the whole group, evidence of iron deficiency as judged by reduced sideroblast counts was common. Normochromic anaemia was frequent, and poor cellularity of the bone-marrow sample was often found, but the two were not closely related.

Despite the prevalence of low serum folic acid concentrations and the general tendency for the serum vitamin- $B_{12}$ concentrations to be reduced, there was no example of megaloblastic anaemia. The work of Read et al. (1965) indicated that old people with low serum folic acid concentrations were, in fact, deficient in folic acid, so that it is likely that the low levels in our patients were also indicative of folic acid deficiency. Presumably the deficiency had not become severe enough to cause recognizable megaloblastic anaemia in our group of patients.

Low blood ascorbic acid concentrations were common in the winter months despite the frequency with which old people ill at home were supplied with fruit juices rich in ascorbic acid. Any deficiency that there may have been was not sufficient to cause clinical scurvy.

Megaloblastic haemopoiesis due to folate deficiency in seven patients with peripheral neuritis and/or myelopathy was described by Grant et al. (1965). They thought that the most plausible explanation for the association was that neurological disease caused folate deficiency by interfering with appetite. This may have led to deficiency of other vitamins necessary for nerve function. Improvement brought about by folic acid in some cases may have been associated with improved appetite and subsequent improved intake of unknown factors.

Reduced serum folic acid levels and megaloblastic anaemia have been described in epileptics receiving anticonvulsant treatment. Malpas et al. (1966) confirmed that folic acid levels were often low in such patients, and they thought that anticonvulsant drugs which included barbiturates played a part along with nutritional deficiency. Fifteen of our patients had been taking barbiturates within one month before admission, but only three of these had subnormal serum folic acid levels.

Inquiry into the food intake of our patients led us to believe that this was often poor, but the difficulty of making an assessment on newly admitted gravely ill patients is very grear and accurate information is lacking. In many cases there seemed to be no lack of availability of food; for instance, there was no greater tendency for low serum folic acid levels to occur among those living alone than among those living with younger relatives. The association with organic brain disease in our patients and of cord or peripheral nerve disease in the cases of Grant et al. (1965) suggested that physical disability or illness and disinterest in food were important factors. The part played by barbiturates is not clear, but interest in food might be blunted by treatment with them. In some cases sufficient suitable food was probably not available because of loss of interest, difficulty in swallowing, immobility, or poverty.

Reduced intake of food and malabsorption seem to be the two more likely causes of our findings and those of Read et al. (1965). We are puzzled by the lack of multiple deficiencies in the same patient on either score. Marked individual idiosyncrasy of diet might be responsible, but this seems unlikely. Malabsorption would tend to cause combined deficiencies of several factors in the same patient. In any case malabsorption on such a wide scale would be unlikely unless some process such as subclinical mesenteric ischaemia was much more widespread than is at present recognized.

It has recently been suggested that vitamin supplements would be of value to the elderly person living alone and that folic acid in doses of $25-50 \mu \mathrm{g}$. a day be given (Read et al., 1965). Before such treatment is generally adopted it is our view that the problem should be more clearly defined. Our findings did not suggest that the old person at home alone was more likely to be deficient in these than a person living with relations. If apathy and disinterest and physical disability are more important than lack of availability of food then the provision of dietary supplements will be unlikely to solve the problem, for the supplement will be no more likely to be eaten than the food. Such supplements might even be dangerous in elderly people who could not be relied on not to exceed the recommended dose. In our view, if folic acid is given to the elderly, consideration should also be given to the need for providing parenteral vitamin- $\mathrm{B}_{12}$ treatment in addition.

\section{Summary}

Patients newly admitted to a geriatric department for various reasons often showed evidence of iron deficiency and low serum folic acid concentrations. Serum vitamin- $B_{13}$ concentrations and blood ascorbic acid concentrations were also diminished. An association between organic brain disease and low serum folic acid was found. Possible reasons for the finding are discussed.

We are indebted to Professor L. J. Witts and Dr. Sheila Callender for advice, to Mr. J. R. P. O'Brien for facilities in the Nuffield Department of Clinical Biochemistry, to Mr. A. Barr for statistical analyses, and to Dr. L. Cosin for facilities at Cowley Road Hospital.

Requests for reprints should be addressed to Dr. F. G. Bolton, Churchill Hospital, Oxford.

\section{REFERENCES}

Bedford, P. D., and Wollner, L. (1958). Lancet, 1, 1144.

Boger, W. P., Wright, L.' D., Strickland, S. C., Gylfe, J. S., and (N.Y), 89, 375, Cape, R. D. T., and Shinton, N. K. (1961). Geront. clin. (Basel), 3, 163. how, B. F., Wood, R., Horonick, A., and Okuda, K. (1956). F. Geront., 11, 142.

Denson, K. W., and Bowers, E. F. (1961). Clin. Sci., 21, 157.

Douglas, A. S., and Dacie, J. V. (1953). F. clin. Path., 6, 307.

Droller, H., and Dossett, J. A. (1959). Geront. clin. (Basel), 1, 96

Gaffney, G. W., Horonick, A., Okuda, K., Meier, P., Chow, B. F., and Shock, N. "W. (1957). \%. Geront., 12, 32.

Geill, T. (1962). Geront. clin. (Basel), Additamentum, p. A150.

Grant, H C., Hoffbrand, A. V., and Wells, D. G. (1965). Lancet, 2, 763.

Hansen, H. A., and Nyström, B. (1961). Geront. clin. (Basel), 3, 173.

Kaplan, E., Zuelzer, W. W., and Mouriquand, C. (1954). Blood, 9, 203.

Killander, A. (1957). Acta paediat. (Uppsala), 46, 585.

King Edward's Hospital Fund for London, 1965, 69th Annual Report.

Lawrence, A. C. K. (1959). Iron Therapy and the Blood in Pregnancy. M.D. Thesis. London.

Lawson, I. R. (1960). Geront. clin. (Basel), 2, 87 Malpas, J. S., Spray, G. H., and Witts, L. J. (1966). Brit. med. J., 1,

Medical Research Council (1953). Spec. Rep. Ser. med. Res. Coun. (Lond.), No. 280

Mollin, D. L., and Ross, G. I. M. (1952). F. clin. Path., 5, 129

Read, A. E., Gough, K. R., Pardoe, J. L., and Nicholas, A. (1965). Brit. med. F., 2, 843.

Roe, J. H., and Kuether, C. A. (1943). F. biol. Chem., 147, 399.

Spray, G. H. (1955). Clin. Sci., 14, 661.

Spray, G. H. (1955). Clin. Sci., 14,661. 